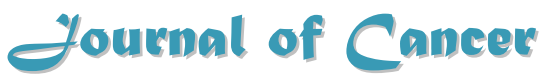

2010; 1:32-37

Research Paper

(C) Ivyspring International Publisher. All rights reserved

\title{
Tumor cell budding from focally disrupted tumor capsules: a common pathway for all breast cancer subtype derived invasion?
}

\section{Yan-gao Man ${ }^{凶}$}

Gynecologic and Breast Research Laboratory, Armed Forces Institute of Pathology and American Registry of Pathology, Washington DC, USA, and Jilin University, China

$\triangle$ Corresponding author: Yan-gao Man, MD., PhD., Director of Gynecologic and Breast Research Laboratory, Department of Gynecologic and Breast Pathology, Armed Forces Institute of Pathology and American Registry of Pathology. Tel: 202-782-1612; Fax: 202-782-3939; E-mail: man@afip.osd.mil

Published: 2010.06.02

\begin{abstract}
Human breast cancer represents a group of highly heterogeneous lesions consisting of about 20 morphologically and immnohistochemically distinct subtypes with substantially different prognoses. Our recent studies have suggested that all breast cancer subtypes, however, may share a common pathway, tumor cell budding from focally disrupted tumor capsules, for their invasion. The potential mechanisms and clinical implications of our observations are discussed.
\end{abstract}

Key words: Breast cancer heterogeneity; Breast cancer invasion; Cell budding; Basement membrane; Myoepithelial cell layer

\section{Introduction}

Human breast cancer represents a group of highly heterogeneous lesions, consisting of about 20 morphologically distinct subtypes $[1,2]$. Breast cancers also have highly variable molecular and immunohistochemical signatures, and could be roughly divided into 5-categories based on expression of estrogen receptor (ER), progesterone receptor (ER), human epidermal growth factor receptor-1 and 2 (HER-1 and 2), and cytokeratins 5/6 [3-5]. The clinical course and prognosis of these subtypes differ substantially. Inflammatory and pregnancy-associated breast cancers have the most aggressive clinical course, in which many tumors had undergone extensive invasion or metastasis at the diagnosis [6-9]. In sharp contrast, small tubular and mucinous carcinomas have the most indolent clinical course, in which most pre-invasive tumors do not progress during patients' lifetime [1,2].

Despite the substantial differences in the morphology and immunohistochemistry, all breast cancer subtypes are likely to share a common pathway for invasion due to their common structural features. The epithelium of all normal and pre-invasive breast cancers is physically separated from the stroma and vascular structures by a dense fibrous capsule consisting of the basement membrane and a layer of myoepithelial cells (except tubular carcinoma), which are permanent structural elements and are largely independent of hormonal regulation and biophysiological condition [10-12] (Fig 1). Thus, the disruption of the tumor capsule is a pre-requisite for all breast cancer subtype derived invasion.

\section{Tumor cell budding from focally disrupted tumor capsules}

As the absence of the myoepithelial cell layer is one of the most distinct morphological features of invasive breast lesions, our recent studies have attempted to elucidate the early alterations of the myoepithelial cells and their impact on associated 
epithelial cells during tumor progression. Our studies of about 1,000 cases of human breast tumors revealed that a subset of pre-invasive tumors harbored focal disruptions (the absence of myoepithelial cells resulting in a gap larger than the combined size of at least 3-epithelial cells) in the surrounding tumor capsules. The frequency of focal disruptions varied significantly, from none in a majority of the cases to about $1 / 3$ of the pre-invasive tumor nests showing focal tumor capsule disruptions in about $15 \%$ of the cases [13-17].

Focal disruptions in the tumor capsule appear to substantially impact both the morphological and biological presentations of associated epithelial cells. Epithelial cells overlying these focal disruptions were generally arranged as tongue- or finger-like projections. Cells within different projections from the same case or different cases were morphologically similar, but they often differed substantially in size, shape, density, and polarity from adjacent cells within the same tumor. These cell projections also displayed the following unique features:

\subsection{Morphological signs of stromal invasion}

The size of these cell projections varied from a few to over 100 individual cells. Some large cell projections penetrated deep into the stroma, and cells at the tip of projections were often disassociated from the tumor core (Fig 2). Focal tumor capsule disruptions with budding cells were seen in all breast cancer subtypes with a higher frequency in aggressive and lower frequency in indolent lesions.

\subsection{The loss of estrogen receptor (ER) expres- sion}

All or nearly all the cells within a vast majority (over $86 \%$ ) of the budding cell projections overlying focally disrupted tumor capsules were consistently devoid of ER expression, whereas all or nearly all adjacent cells within the same tumors were strongly positive for ER (Fig 3).

\subsection{Cytoplasmic expression of HER-2 and E-cadherin}

A majority of these cell projections showed substantially elevated expression of HER-2 and cell surface adhesion molecule E-cadherin [18,19]. The sub-cellular localization of both HER-2 and E-cadherin, however, was cytoplasmic, rather than the typical membrane-association [18,19] (Fig 4).

\subsection{Significantly higher frequency of loss of he- terozygosity (LOH)}

In 5 selected cases, these budding cell projections overlying focally disrupted tumor capsules and adjacent counterparts within the same tumor were microdissected and assessed for $\mathrm{LOH}$. Budding cell projections had significantly higher or different $\mathrm{LOH}$ in 10 of the 15 markers [13] (Fig 5).

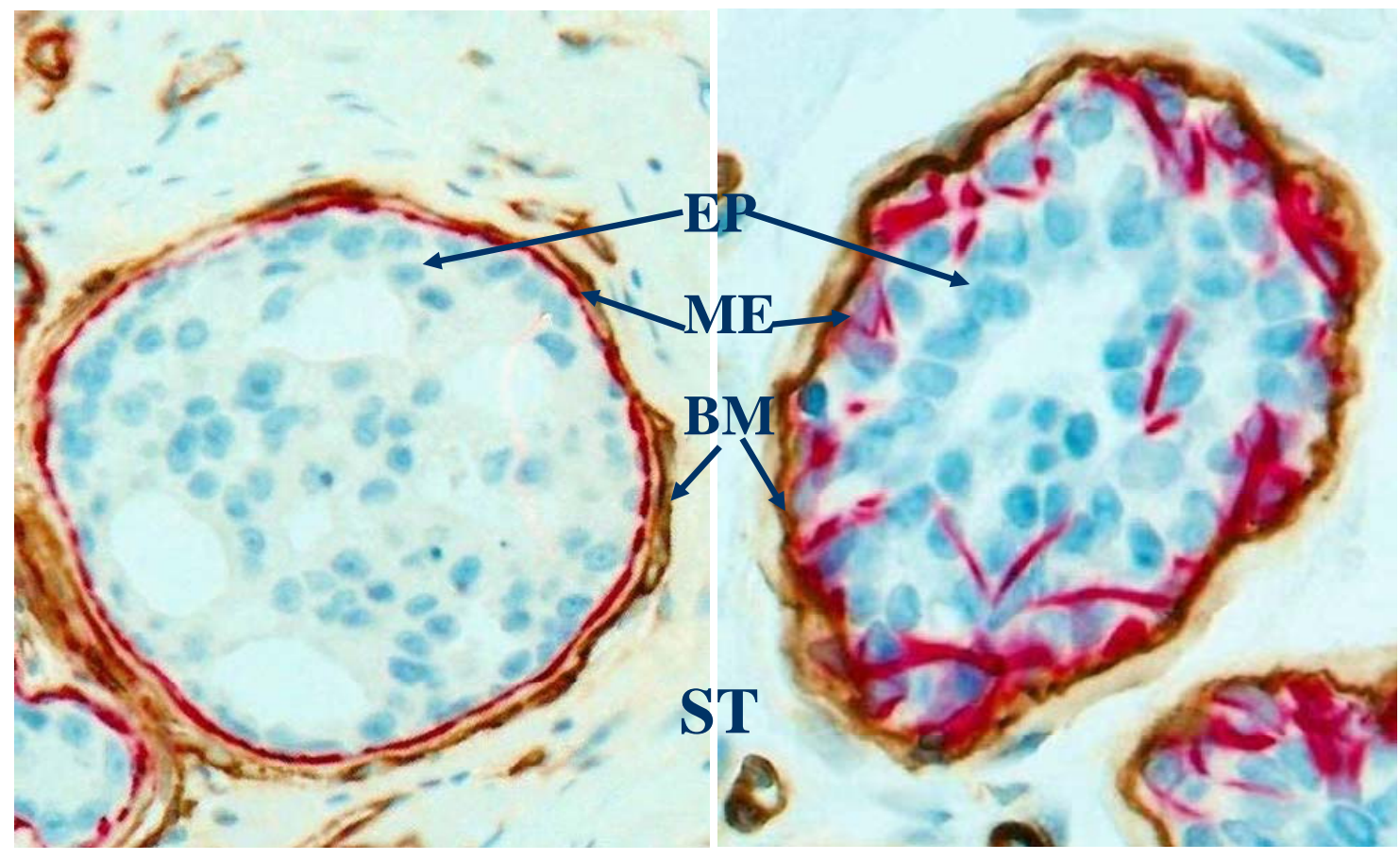

Fig I. Structural relations among epithelium (EP), myoepithelium (ME), basement membrane (BM) and stroma (ST). Human breast sections were double immunostained for smooth muscle actin (red) and collagen IV (brown). 500X. 

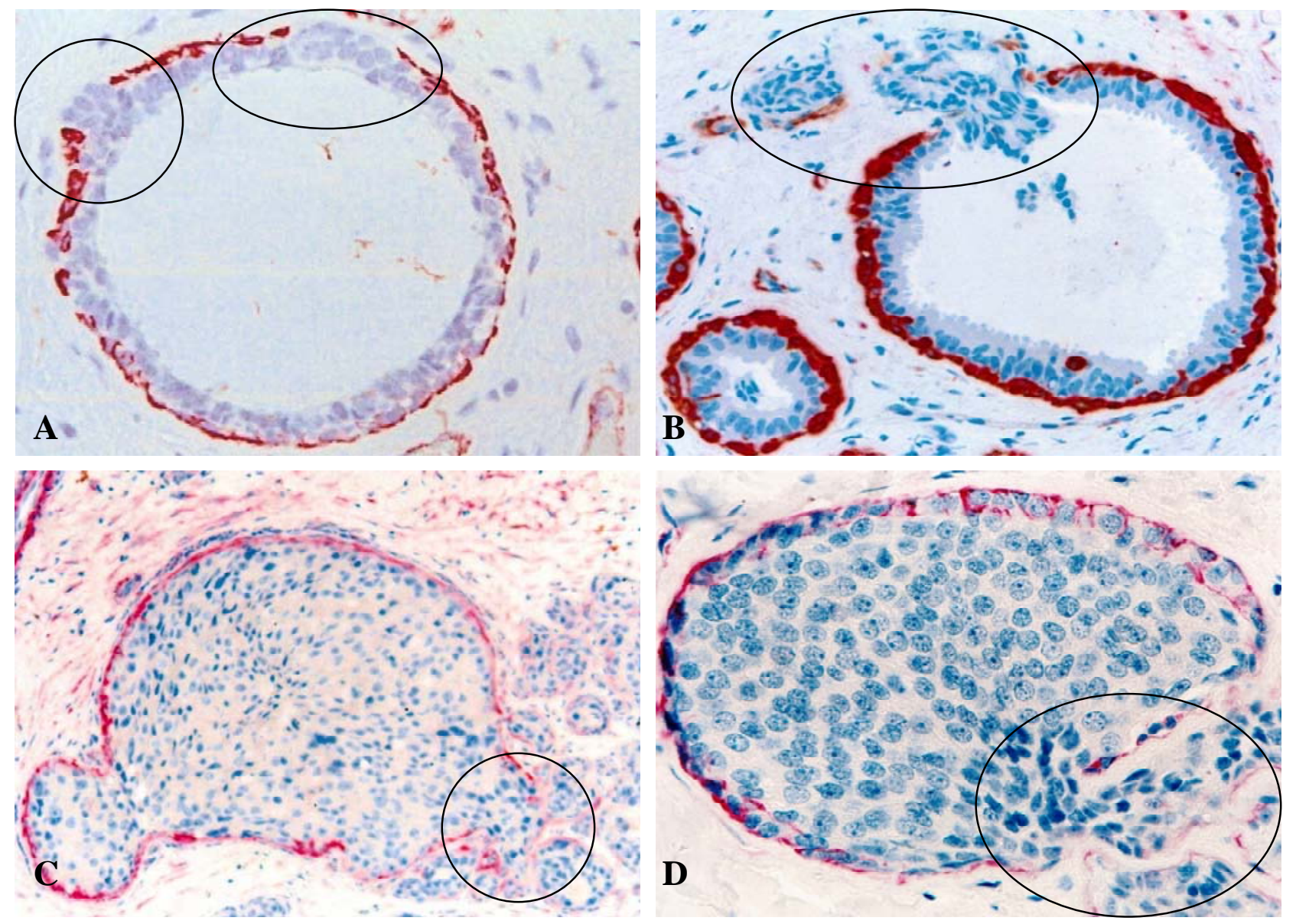

Fig 2. Focal capsule disruptions with budding tumor cells. Human breast tissue sections were immunostained with a tumor capsule maker, sooth muscle actin (SMA) (red). Circles identify budding tumor cells overlying focally disrupted tumor capsule. Note that tumor cells at the tips of the projections are often dissociated from the tumor core. 300X.
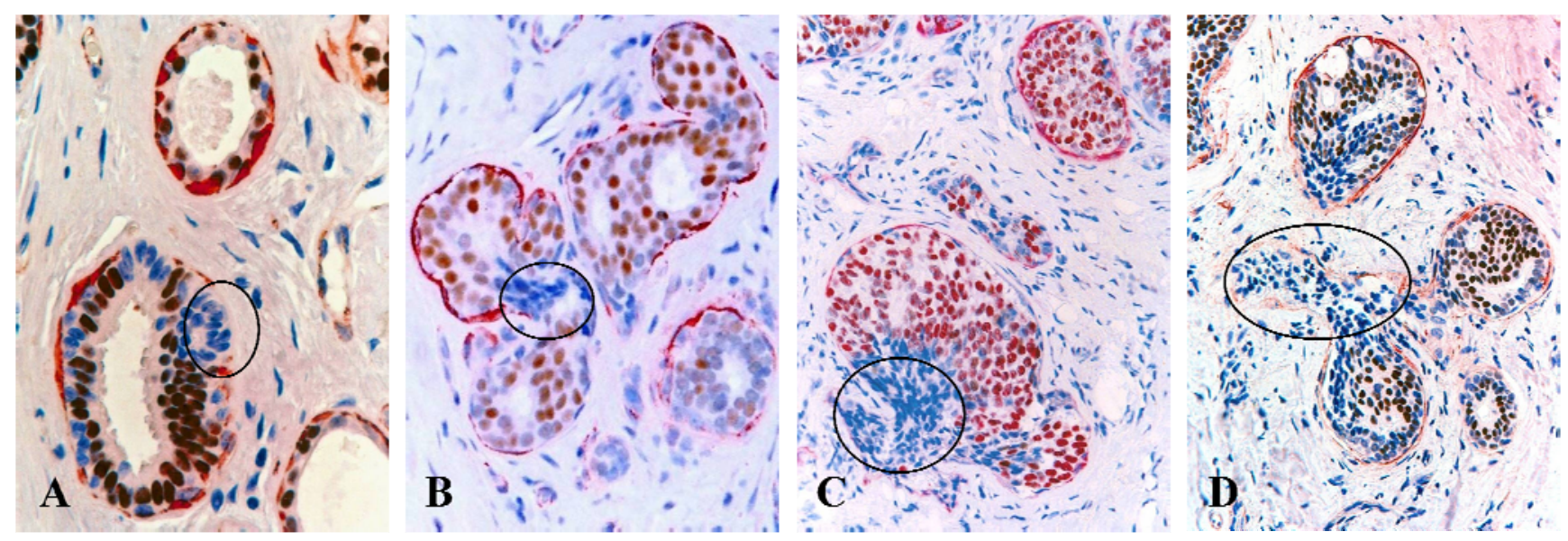

Fig 3. Loss of ER expression in cell projections overlying focally disrupted tumor capsules. Human breast tissue sections from 4 different cases were double immunostained for SMA (red) and ER (brown). Circles identify budding cell projections overlying focally disrupted tumor capsules. Note that although these tumors represent morphologically different subtypes, all the budding cell projections overlying focally disrupted tumor capsules share a very similar immunohistochemical and morphological profile. 100X. 

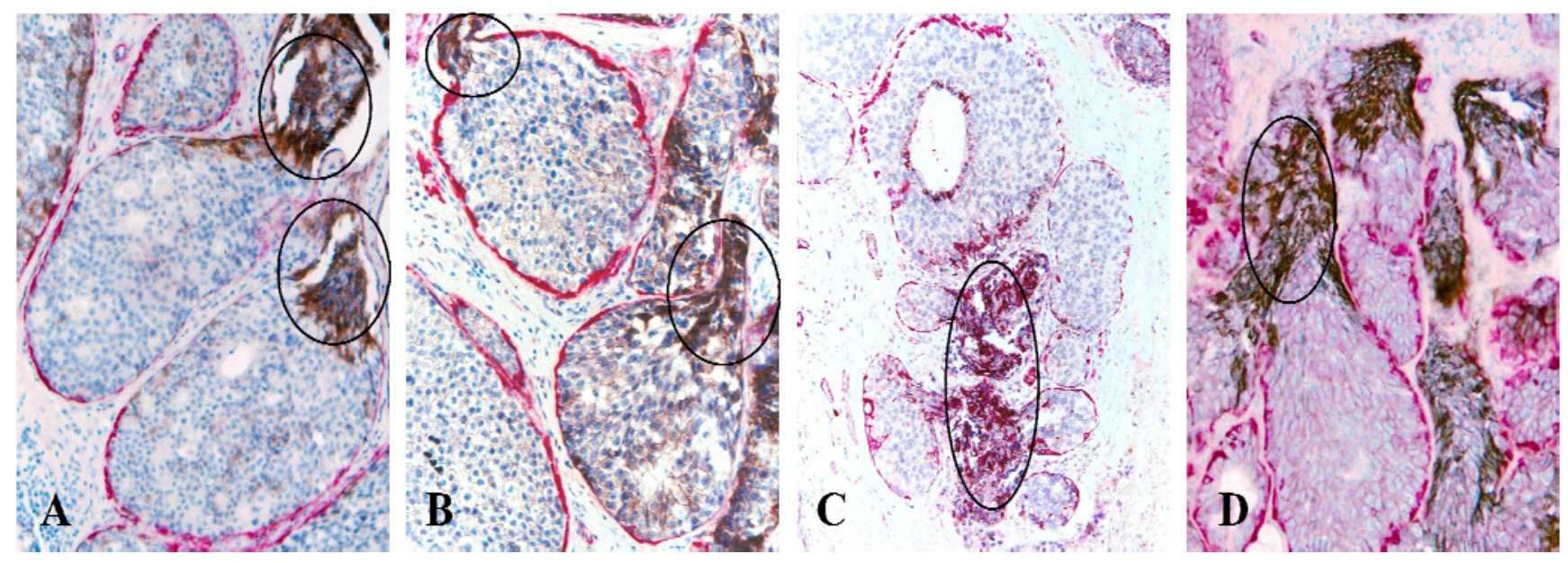

Fig 4. Cytoplasmic expression of HER-2 (A-B) and E-cadherin (C-D). Human breast tissue sections from four different cases were double immunostained for SMA (red) and E-cadherin or HER-2 (black). Circles identify elevated cytoplasmic expression of HER-2 and E-cadherin exclusively or preferentially in budding cell projections overlying focally disrupted tumor capsules.
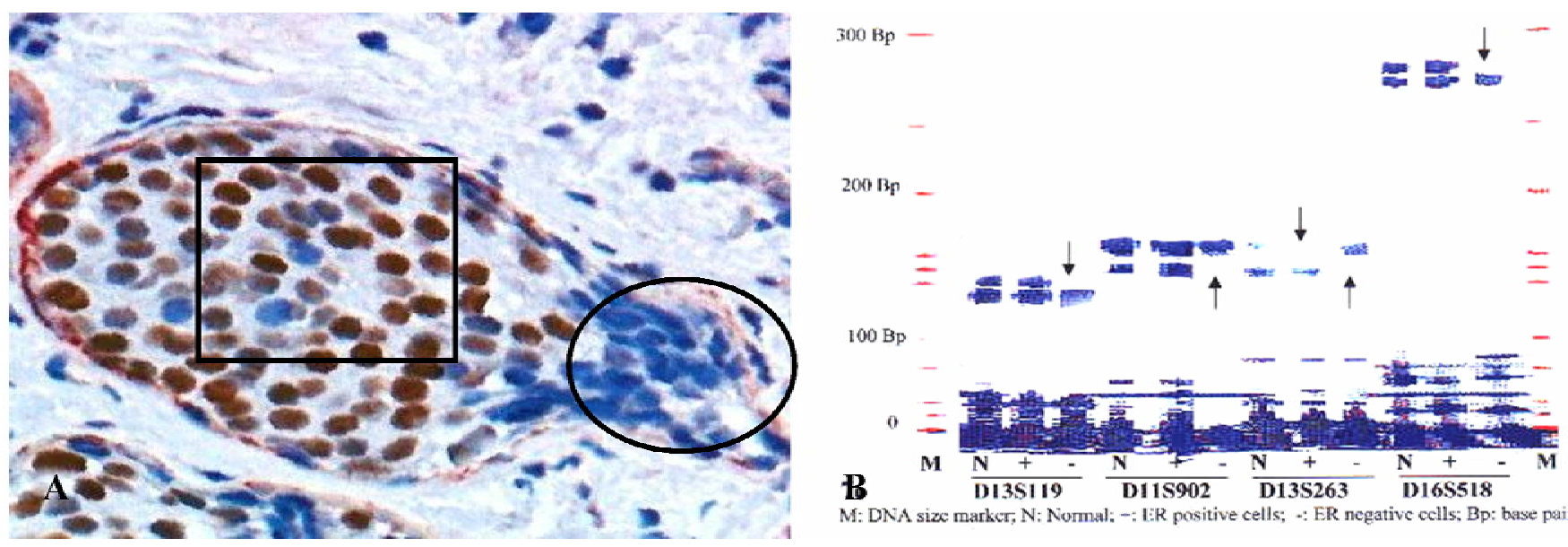

Fig 5. A higher frequency of genetic instabilities in cell projections overlying focally disrupted tumor capsule. A human breast tissue section was double immunostained for SMA (red) and ER (brown). Circle identifies microdissected ER negative cell projections overlying the focally disrupted tumor capsule. Square identifies ER positive cells within the tumor core. Arrows identify LOH.

Although tumor cell budding from focally disrupted tumor capsules was seen in all breast cancer subtypes, the frequency and size of the capsule disruptions and the cell projections varied significantly among different subtypes. Large focal disruptions and large budding cell projections (with about 100 individual cells) were exclusively or preferentially seen in duct-derived and clinically more aggressive subtypes. Clinically indolent tubular carcinoma has the lowest frequency of tumor capsule disruptions with budding tumor cells (not shown).

\section{Potential mechanism(s) of tumor capsule disruptions and tumor cell budding}

It is a commonly held belief that the disruption or degradation of the tumor capsules is triggered primarily, if not solely, by an overproduction of proteolytic enzymes produced by cancer or stromal cells [20-22]. This belief, however, is hard to reconcile with two main facts. First, although most pre-invasive breast cancers show high levels of proteolytic enzyme expression, only about $30 \%$ of them show the degra- 
dation of the tumor capsules and subsequent invasion [23-27]. Second, results from worldwide human clinical trials with a wide variety of proteolytic enzyme specific inhibitors to treat or prevent tumor invasion have been very disappointing $[28,29]$.

Based on results from our recent studies [13-19], we have proposed that tumor capsule degradation and tumor invasion is triggered by focal myoepithelial cell degeneration-induced autoimmunoreactions that cause focal disruptions in the tumor capsule, which selectively favor monoclonal proliferation of tumor stem cells or biologically more aggressive cell clones overlying the focal disruptions [30]. The rationale of our hypothesis is that: since the myoepithelial cell layer is the sole source of several tumor suppressors and the epithelium is normally devoid of blood vessels and lymphatic ducts, a focal disruption in the tumor capsule is likely to have several consequences: (1) a localized loss of tumor suppressors and paracrine inhibitory functions, which confers tumor cell growth advantages to escape from the programmed cell death [31,32], (2) a localized increasing of permeability for nutrients and growth factors, and altered oxygen level, which selectively favors the proliferation of progenitor or stem cells [33,34], (3) a localized increasing of leukocyte infiltration, which directly export growth factors to tumor cells through direct physical contact [35,36], and (4) the direct tumor-stromal cell contact, which augments the expression of stromal MMP or represses the expression of E-cadherin and other cell surface adhesion molecules, which facilitates epithelial-mesenchymal transition $[37,38]$. These alterations could individually or collectively lead to increasing proliferation and motility in tumor cells overlying focally disrupted tumor capsules.

\section{Clinical implications of tumor cell budding from focally disrupted tumor capsules}

Together, our findings suggest that tumor cell budding from focally disrupted tumor capsules is likely to represent a common pathway shared by all breast cancer subtypes for their invasion. As the disruption of the tumor capsule is a pre-requisite for tumor invasion, budding cell projections from focally disrupted tumor capsules seen in our studies are likely to represent the direct precursors of invasive lesions. Our findings and speculation are in total agreement with those of previous studies of human esophageal and colorectal cancers, which have shown that tumors with budding cells have a significantly more aggressive clinical course and worse prognosis [39-41]. Thus, microdissecting these budding cell projections for molecular and biochemical analyses could potentially lead to the identification of the specific trigger factors for tumor invasion. The development of a quantitative immunohistochemical assay to measure the frequency and extent of tumor capsule disruptions with budding cells may significantly facilitate early detection of pending invasive tumors or patients at greater risk to develop invasive tumors. The development of therapeutic agents to specifically target these budding tumor cell projections could potentially provide the most effective regimen for early intervention and prevention of breast cancer invasion. However, it is currently very difficult, if not impossible, to fully elucidate the molecular and biochemical profiles of these very limited budding cells, due to the lack of sensitive technical approaches.

\section{Acknowledgment}

This study was supported in part by grant BCTR0706983 from The Susan G. Komen Breast Cancer Foundation, grant 2008-02 from US Military Cancer Institute and Henry M. Jackson Foundation, grants DAMD17-01-1-0129 and DAMD17-01-1-0130 from Congressionally Directed Medical Research Programs, grant 2006CB910505 from the Ministry of Chinese Science and Technology Department, and grant 30801176 from The National Natural Science Foundation of China.

The opinions and assertions contained herein represent the personal views of the author and are not to be construed as official or as representing the views of the Department of the Army or the Department of Defense.

\section{Conflict of Interest}

The author has declared that no conflict of interest exists.

\section{References}

1. Rossen PP. Rosen's breast pathology. Philadelphia, PA: Lippncott Williams \& Wilkins, 2001.

2. Tavassoli FA. Pathology of the Breast. New York: Elsevier, 1992.

3. Cianfrocca M, Gradishar W. New molecular classification of breast cancer. CA Cancer J Clin 2009; 59(5):303-313.

4. Tang P, Skinner KA, Hicks DG. Molecular classification of breast carcinomas by immunohistochemical analysis: are we ready? Diagn Mol Pathol. 2009;18(3):125-32.

5. Weigelt B, Mackay A, A'hern R, Natrajan R, Tan DS, Dowsett $\mathrm{M}$, et al.. Breast cancer molecular profiling with single sample predictors: a retrospective analysis. Lancet Oncol 2010; 11(4):339-349.

6. Mathelin C, Annane K, Treisser A, Chenard MP, Tomaseeto C, Bellocq JP, Rio MC. Pregnancy and post-partum breast cancer: a prospective study. Anticancer Res 2008; 28(4C): 2447-2452.

7. Rodriguez AO, Chew H, Cress R, Xing G, McEivy S, Danielsen B, Smith L. Evidence of poorer survival in pregnancy-associated breast cancer. Obstet Gynecol 2008; 112(1):71-78. 
8. Mego M, DeGiorgi U, Hsu L, Ueno NT, Valero V, Jackson S, et al. Circulating tumor cells in metastatic inflammatory breast cancer. Ann Oncol. 2009; 20(11):1824-1828.

9. Man YG, Schwartz A, Levine PH, Teal C, Berg PE. BP1, a putative signature marker for inflammatory breast cancer and tumor aggressiveness. Cancer Biomark. 2009; 5(1):9-17.

10. Gottlieb C, Raiu U, Greenwald KA. Myoepithelial cells in the differential diagnosis of complex benign and malignant breast lesions:an immunohistochemical study. Mod Pathol 1990; 3:135-140.

11. Guelstein VI, Tehypysheva TA, Ermilova VD, Liubimov AV. Myoepithelial and besement membrane antigens in benign and malignant human breast tumors. Int J Cancer 1993; 53:269-277.

12. Bissell MJ, Bilder D. Polarity determination in breast tissue: Desmosomal adhesion, myoepithelial cells, and laminin 1. Breast Cancer Res 2003; 5: 117-119.

13. Man YG, Tai L, Barner R, Vang R, Saenger JS, Shekitka KM, et al. Cell clusters overlying focally disrupted mammary myoepithelial cell layers and adjacent cells within the same duct display different immunohistochemical and genetic features: implications for tumor progression and invasion. Breast Cancer Res 2003; 5: R231-241.

14. Yousefi M, Mattu R, Gao C, Man YG. Mammary ducts with and without focal myoepithelial cell layer disruptions show a different frequency of white blood cell infiltration and growth pattern: Implications for tumor progression and invasion. AIMM 2005; 13:30-37.

15. Man YG, Zhang Y, Shen T, Vinh TN, Zeng $X$, Tauler J, et al. cDNA expression profiling identifies elevated expressions of tumor progression and invasion related genes in cell clusters of in situ breast tumors. Breast Cancer Res Treat 2005; 89:199-208.

16. Man YG, Zhao CQ, Wang J. Breast tumor cell clusters and their budding derivatives show different immunohistochemical profiles during stromal invasion: implications for hormonal and drug therapies. Cancer Therapy 2006; 4: 193-204.

17. Man YG, Nieburgs HE. A subset of cell clusters with malignant features in morphologically normal and hyperplastic breast tissues. Cancer Detect Prev 2006; 30 (3): 239-247.

18. Zhang XC, Hashemi SS, Yousefi M, Gao CL, Sheng J, Mason J, Man YG. Atypical expression of c-erbB2 in cell clusters overlying focally disrupted breast myoepithelial cell layers: a potential sign for increasing cell motility and invasion. Int J Biol Sci 2008; 4:259-269.

19. Zhang XC, Hashemi SS, Yousefi M, Gao CL, Sheng J, Mason J, Man YG. Atypical expression of E-cadherin in cell clusters overlying focally disrupted mammary myoepithelial cell layers: implications for tumor cell motility and invasion. Pathol Res Pract 2009; 205:375-385.

20. Goldfarb RH, Liotta LA. Proteolytic enzymes in cancer invasion and metastasis. Semin Thromb Hemost 1986; 12: 294-307.

21. Duffy MJ, Maguire TM, Hill Al. Metalloproteinases: role in breast carcinogenesis, invasion and metastasis. Breast Cancer Res 2000; 2: 252-257.

22. Kugler A. Matrix metalloproteinases and their inhibitors. Anticancer Res 1999; 19:1589-1592.

23. Millis RR, Thynne GS. In situ intraduct carcinoma of the breast: a long term follow-up study. Br J Surg 1975; 62:957-962.

24. Rosen PP, Braun DW Jr, Kinne DE. The clinical significance of pre-invasive breast carcinoma. Cancer 1980; 46: 919-925.

25. Page DL, Duppont WD, Rogers LW, Landenberger M. Intraductal carcinoma of the breast: follow up after biopsy only. Cancer 1982; 49:751-758.

26. Page DL, Dupont WD, Rogers LW, Jensen RA, Schuyler PA. Continues local recurrence of carcinoma 15-25 years after a diagnosis of low grade ductal carcinoma in situ of the breast treated only by biopsy. Cancer 1995; 76:1197-2000.
27. Eusebi V, Feudale E, Foschini MP. Long-term follow-up of in situ carcinoma of the breast. Semin Diagn Pathol 1994; 11:223-235.

28. Coussens LM, Fingleton B, Matrisian LM. Matrix metalloproteinase inhibitors and cancer: trial and tribulations. Science 2002; 295 (5564): 2387-2392.

29. Matrisian LM, Sledge GW Jr, Mohla S. Exacellular proteolysis and cancer: meeting summary and future directions. Cancer Res 2003; 63: 6105-6109.

30. Man YG. Focal degeneration of aged or injured myoepithelial cells and the resultant auto-immunoreactions are trigger factors for breast tumor invasion. Med Hypotheses 2007; 69(6):13401357.

31. Brummer T, Schramek D, Hayes VM, Bennett HL, Callon CE, Musgrove EA, Daly RJ. Increased proliferation and altered growth factor dependence of human mammary epithelial cells overexpressing the Gab2 docking protein. J Biol Chem 2006; 281:626-631.

32. Oliveira AM, Ross JS, Fletcher JA. Tumor suppressor genes in breast cancer: the gatekeepers and the caretakers. Am J Clin Pathol 2005; 124(Suppl):S16-28.

33. Chakravarthy MV, Spangenhurg EE, Booth FW. Culture in low levels of oxygen enhances in vitro proliferation potential of satellite cells from old skeletal muscles. Cell Mol Life Sci 2001; 58:1150-1158.

34. Csete M, Walikonis J, Slawny N, et al. Oxygen-mediated regulation of skeletal muscle satellite cell proliferation and adipogrnesis in culture. J Cell Physiol. 2001;189(2):189-96.

35. Freeman MR, Schneck FX, Gognon ML, Corless C, Soker S, Niknejad K, Peoples GE, Klagsburn M. Peripheral blood T-lymphocytes and lymphocytes infiltrating human cancers express vascular endothelianl growth factor: a potential role for T cells in angiogenesis. Cancer Res 1995; 55: 4140-4145.

36. Qu Z. Immunohistological detection of growth factors and cytokines in tissue mast cells. Methods Mol Biol 2006; 315:257-272.

37. Kang Y, Massague J. Epithelial-mesenchymal transition: twist in development and metastasis. Cell 2004; 118: 277-279.

38. Sato T, Sakai T, Noguchi Y, Takita M, Hirakawa S, Ito A. Tumor-stromal cell contact promotes invasion of human uterine cervical carcinoma cells by augmenting the expression and activation of stromal matrix metalloproteinases. Gynecol Oncol 2004; 92: 47-56.

39. Miyata H, Yoshioka A, Yamasaki M, Nushijima Y, Takiguchi S, Fujiwara $Y$, et al. Tumor budding in tumor invasive front predicts prognosis and survival of patients with esophageal squamous cell carcinomas receiving neoadjuvant chemotherapy. Cancer 2009; 115(14): 3324-3334.

40. Wang LM, Kevans D, Mulcahy H, O'Sullivan J, Fennelly D, Hyland J, O'Donoghue D, Sheahan K. Tumor budding is a strong and reproducible prognostic marker in T3N0 colorectal cancer. Am J Surg Pathol 2009; 33(1): 134-141.

41. Hart IR. New evidence for tumor embolism as a model of metastasis. J Pathol 2009; 219 (3): 275-276. 